\title{
Recognition memory and source monitoring
}

\author{
D. STEPHEN LINDSAY \\ Williams College, Williamstown, Massachusetts \\ and \\ MARCIA K. JOHNSON \\ Princeton University, Princeton, New Jersey
}

\begin{abstract}
This study demonstrates a manipulation that has opposite effects on old/new recognition and source monitoring. Deep processing of target items improved performance on an old/new recognition test in which subjects were to discriminate between targets and new distractors, but it impaired performance on a source monitoring test in which subjects were to discriminate between targets and distractors that had also been deeply processed during the experimental session. We argue that the relationship between old/new recognition and source monitoring varies with the specifics of the situation. The aspects of memories that support recognition judgments are not necessarily the same as those that support source monitoring judgments, and memory performance is the joint product of what is stored in memory and how memory is tested.
\end{abstract}

According to the source monitoring model, event memories are attributed to particular sources in one's past experience by means of decision processes performed (often without awareness) during remembering (see, e.g., Hashtroudi, Johnson, \& Chrosniak, 1989; Johnson, 1988; Lindsay \& Johnson, 1987; Lindsay, Johnson, \& Kwon, 1990). The term source refers to a variety of attributes that, collectively, specify the conditions under which an event memory was acquired (e.g., its spatial and temporal context, medium, modality, etc.). Source monitoring processes are involved in the remembering of such things as where and when an event occurred, how it was perceived, and who and what were involved in it. Reality monitoring decisions-discriminations between memories of actual perceived events and memories of imagined, internally generated events-represent a particularly intriguing type of source discrimination (Johnson \& Raye, 1981).

Support for the hypothesis that memories are attributed to particular sources via decision-making during remembering comes from a variety of studies that have demonstrated effects of memory content on source monitoring accuracy. Most of these studies have consisted of a study phase, during which subjects receive information from different sources, followed by a test phase, in which subjects are tested on their ability to identify the source of particular test items. In general, we have found that manipulations that increase the similarity between to-bediscriminated sources lower source monitoring perfor-

Correspondence concerning this manuscript may be addressed to Marcia Johnson, Department of Psychology, Green Hall, Princeton University, Princeton, NJ 08544, or to D. Stephen Lindsay, Department of Psychology, McMaster University, Hamilton, Ontario L8S 4K1, Canada. mance (see Johnson, 1988, and Johnson \& Raye, 1981, for reviews of these studies and discussions of their relation to other areas of the memory literature).

What is the relationship between source monitoring and old/new recognition? Both tasks require that subjects discriminate between test items on the basis of their prior experience with those items. Old/new recognition tests require subjects to differentiate between items that were and were not presented during a study phase, whereas source monitoring tests require subjects to differentiate between items that were presented via different sources during a study phase. A number of memory researchers have explored questions relevant to the relationship between recognition and source monitoring (e.g., Anderson \& Bower, 1974; Atkinson \& Juola, 1973; Jacoby, Woloshyn, \& Kelley, 1989; Johnson \& Raye, 1981; Mandler, 1980; Raye, 1976; Underwood \& Freund, 1970; Winograd, 1968), and, taken together, their work suggests that the relationship between these tasks will depend on the specifics of the situation.

We have often found that old/new recognition is unaffected by manipulations that clearly alter source monitoring accuracy. For example, in Lindsay et al. (1990), subjects were more likely to misremember which of two people had made a particular statement if the two people were similar to one another rather than dissimilar, but this similarity manipulation had no effect on recognition memory for the statements. It is likely, however, that some manipulations would have parallel effects on recognition and source monitoring performance, and that there are also variables that would have little effect on source monitoring but large effects on recognition. The current study was contrived as a demonstration of a manipulation that has opposite effects on old/new recognition and source monitoring performance. 


\section{METHOD}

\section{Subjects}

The subjects were 40 Princeton University undergraduate students, who received a nominal payment for participating.

\section{Materials and Procedure}

A set of 60 medium-frequency nouns was selected from the Kučera and Francis (1967) norms and randomly divided into three sets of 20 words. Each word was printed on a $3 \times 5$ in. card. During the acquisition phase, words from two sets were presented 1 at a time in a randomly interleaved order, with the constraint that no more than 2 words from a given set occur in immediate succession. The words from one set were presented on the subject's right and the words from the other set on the subject's left. The subjects were not warned of a memory test; instead, they were simply instructed to perform a task with each word as it was presented: In the deep-deep condition, the subjects made up a sentence that contained the word; in the deep-shallow condition, the subjects made a sentence that contained the word if it was presented on the left, and counted the number of Es in the word if it was presented on the right.

At test, all subjects were tested on their ability to identify words that had been presented on the right. Thus subjects in the deep-deep condition were to identify words that they had processed at a relatively "deep" level, whereas subjects in the deep-shallow condition were to identify words they had processed at a relatively "shallow" level (Craik \& Lockhart, 1972).

There were two test conditions, which differed by virtue of the nature of the distractor items on the test. Half of the subjects in each orienting condition were given an old/new recognition test, in which the 20 target words that had been presented on their right were randomly intermixed with 20 new words that were not presented during the sudy phase. The remaining subjects were given a source monitoring test, which consisted of the 20 target words that had been presented on their right, randomly intermixed with the 20 words that had been presented on their left. In both testing conditions, the subjects were instructed to circle each word that had been presented on their right. The subjects were assigned to orienting task and test condition according to a predetermined schedule. Within each of these between-subjects groups, each word set was used equally often as right and left and new words.
Levels of processing theory (e.g., Craik \& Lockhart, 1972) predicts that in the old/new test condition, subjects who had made sentences with the target words would do better than those who had counted Es in the target words. Source monitoring theory predicts that in the source monitoring test condition, subjects who had counted Es in the target words would do better than those who had made sentences with them. The latter prediction follows from the fact that it was only when the targets were processed at a shallow level that the orienting task could provide a cue to differentiating between words presented on the right (targets) and words presented on the left (distractors on the source monitoring test).

\section{RESULTS}

The mean percent correct target identifications (of items that had been presented on the right) are presented in Figure 1. As predicted, in the old/new test condition subjects who had made up sentences with the target words recognized more of them than did those who had merely counted the number of Es [means of $89 \%$ and $77 \%$, respectively, $\left.F(1,36)=6.21, M S_{\mathrm{e}}=5.03\right]$. In the source monitoring test condition, on the other hand, subjects who had counted the number of Es in the target words identified more of them than did those who had made up sentences [means of $83 \%$ and $65 \%$, respectively, $F(1,36)=$ $\left.12.88, M S_{\mathrm{e}}=5.03\right]$. This interaction between orienting task and test condition was reliable $\left[F(1,36)=18.49, M S_{\mathrm{e}}\right.$ $=5.03]$.

\section{DISCUSSION}

As predicted, subjects were better at discriminating between words that had been presented on their right and left if they had performed different orienting tasks with the words on each side than they were if they had performed the same orienting task with the words on both sides. Thus it appears that subjects can use information about the kinds

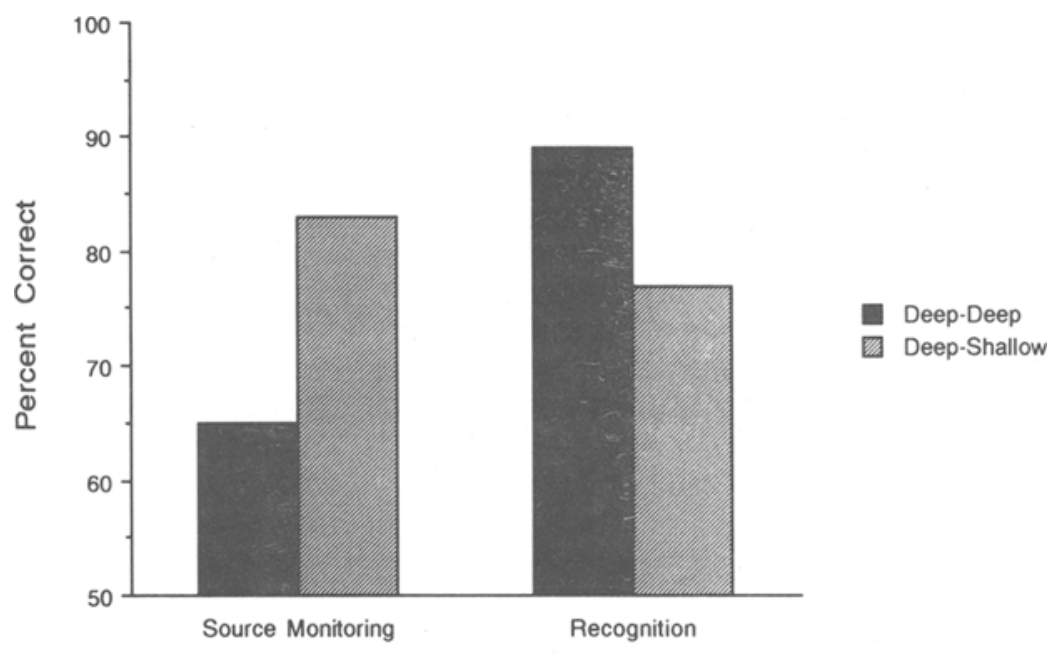

Test Condition

Figure 1. Mean percent target identification as a function of orienting task and test condition. 
of cognitive operations associated with potential sources to identify the source of memories.

Also as predicted, subjects were better at discriminating between old and new words if the targets had been processed at a deep level. This finding comes as no surprise; such effects are well known (see, e.g., Craik \& Tulving, 1975; Lockhart, Craik, \& Jacoby, 1976). The important point is that the conditions that led to superior recognition performance were precisely those that led to inferior source monitoring performance. Of course, the situation was contrived to obtain this particular pattern, and other patterns of relationships between recognition and source monitoring would be obtained in other situations. Nonetheless, the current findings demonstrate that the aspects of memories that support recognition judgments are not necessarily the same as those that support source monitoring judgments, and that memory performance is the joint product of what is stored in memory and how memory is tested (Bransford, Franks, Morris, \& Stein, 1979; Tulving, 1984).

\section{REFERENCES}

ANDERSON, J. R., Bower, G. H. (1974). A propositional theory of recognition memory. Memory \& Cognition, 2, 406-412.

AtKInSON, R. C., \& Juola, J. F. (1973). Factors influencing speed and accuracy of word recognition. In S. Kornblum (Ed.), Attention and performance (Vol. 4, pp. 583-612). New York: Academic Press.

Bransford, J. D., Franks, J. J., Morris, C. D., \& SteIn, B. S. (1979). Some general constraints on learning and memory research. In $\mathrm{L} . \mathrm{S}$. Cermak \& F. I. M. Craik (Eds.), Levels of processing and human memory (pp. 331-354). Hillsdale, NJ: Erlbaum.

CRAIK, F. I. M., \& LOCKHART, R. S. (1972). Levels of processing: A framework for memory research. Journal of Verbal Learning \& Verbal Behavior, 11, 671-684.

Hashtroudi, S., Johnson, M. K., \& Chrosniak, L. D. (1989). Aging and source monitoring. Psychology \& Aging, 4, 106-112.

JACOBY, L. L., WoloshyN, V., \& Kelley, C. M. (1989). Becoming famous without being recognized: Unconscious influences of memory produced by dividing attention. Journal of Experimental Psychology: General, 118, 115-125.

JoHnson, M. K. (1988). Discriminating the origin of information. In T. F. Oltmanns \& B. A. Maher (Eds.), Delusional beliefs: Interdisciplinary perspectives (pp. 34-65). New York: Wiley.

Johnson, M. K., RAYE, C. L. (1981). Reality monitoring. Psychological Review, 88, 67-85.

Kučera, H., Francis, W. N. (1967). Computational analysis of present-day American English. Providence, RI: Brown University Press.

LindsAY, D. S., Johnson, M. K. (1987). Reality monitoring and suggestibility: Children's ability to discriminate among memories from different sources. In S. J. Ceci, M. P. Toglia, \& D. F. Ross (Eds.), Children's eyewitness memory (pp. 92-121). New York: Springer.

Lindsay, D. S., Johnson, M. K., KWON, P. (1990). Developmental changes in memory source monitoring. Manuscript submitted for publication.

LockHart, R. S., Craik, F. I. M., \& Jacoby, L. L. (1976). Depth of processing, recognition, and recall. In J. Brown (Ed.), Recall and recognition (pp. 75-102). New York: Wiley.

MANDLER, G. (1980). Recognizing: The judgment of previous occurrence. Psychological Review, 87, 252-271.

RAYE, C. L. (1976). Recognition: Frequency or organization? American Journal of Psychology, 89, 645-658.

TulviNG, E. (1984). Precis of elements of episodic memory. Behavioral \& Brain Science, 7, 223-268.

UNDERWOOD, B. J., \& Freund, J. S. (1970). Testing effects in the recognition of words. Journal of Verbal Learning \& Verbal Behavior, 9. 117-125.

WINOGRAD, E. (1968). List differentiation, recall, and category similarity. Journal of Experimental Psychology, 78, 510-515.

(Manuscript received September 8, 1990.) 